\title{
The moderating role of political affiliation in the link between flooding experience and preparedness to reduce energy use
}

\author{
Charles A. Ogunbode ${ }^{1}$, Yue Liu \& Nicole Tausch \\ School of Psychology and Neuroscience, University of St Andrews, UK
}

(manuscript accepted for publication in Climatic Change)

\begin{abstract}
Research suggests that highlighting links between local weather events and climate change can help promote climate change engagement. Yet, the evidence for the relationship between weather experiences and climate change attitudes has been mixed. Here we argue that obtaining an accurate assessment of the contribution of weather experiences to climate change engagement necessitates explicit evaluation of factors such as values and identities that influence the way weather experiences are interpreted and integrated into climate change attitudes. We re-analysed data from a prior study in which reported flood experience was found to be indirectly linked to preparedness to reduce energy use among UK residents. Overall, flood experience was positively linked with perceived vulnerability and negatively linked with uncertainty about climate change, but the purported indirect relationship between flood experience and preparedness to reduce energy use was observed among left and not right-leaning voters. We concluded that assessing interactions between extreme weather experiences and political affiliation lends valuable nuance to evaluation of the effects of such experiences on climate change perceptions and attitudes. Highlighting links between climate change and flooding may have varying levels of influence on climate change engagement depending on individuals' political affiliation.
\end{abstract}

Keywords: Climate Change, Experience, Extreme Weather, Values, Political Affiliation

\section{Introduction}

Research suggests that 'proximizing' climate change (i.e. framing the issue as more immediate, relevant and real) can promote pro-environmental behaviour and help mobilize public support for mitigation and adaptation policies (Lorenzoni et al. 2007; Spence et al. 2012; McDonald et al. 2015). Proximizing climate change has the potential to motivate individuals to act pro-environmentally by

\footnotetext{
${ }^{1}$ Corresponding author. Charles A Ogunbode, School of Psychology and Neuroscience, University of St Andrews, St Mary's Quad South Street, St Andrews KY16 9JP. Email: cao6@st-andrews.ac.uk, Tel: 01334 426339.
} 
(1) making climate change consequences more personally relevant and easier to visualize, (2) creating feelings of personal vulnerability and concern, and (3) decreasing the psychological distance of climate change among individuals with a responsibility or capacity for action (see Weber 2006; Brügger et al. 2015; Jones et al. 2017). Advancing from this premise, researchers have indicated that highlighting the links between local weather events and global climate change may be an effective strategy to proximize climate change and galvanize public action (Spence et al. 2011; Taylor et al. 2014).

It is practically impossible to detect the evidence of climate change through casual weather observations. Yet, personal experience of extreme weather events associated with climate change (such as flooding or heatwaves) has been linked to climate change belief, concern and willingness to act pro-environmentally (Akerlof et al. 2013; Myers et al. 2013; Konisky et al. 2015; Demski et al. 2017). However, there are also indications that many people see extreme weather and climate change as separate issues. Perceived vulnerability to extreme weather events may readily change in accordance with local experiences, but such change in perceptions does not invariably culminate in a shift in attitudes regarding climate change (Whitmarsh 2008; Dessai and Sims 2010; Bruine de Bruin et al. 2014).

The evidence for the psychological effects of extreme weather experiences is seemingly beset by contradictions. This is due in part to flawed operationalisations of the concept in previous research (see also Demski et al. 2017) and a common neglect to account for key intervening variables, such as values and identities, that modulate the way people interpret their experiences with extreme weather (Fielding and Hornsey 2016). In this article, we present a re-analysis of data from a prior study purporting a link between flood experience and preparedness to engage in climate change mitigation behaviour in the United Kingdom. We address the plausible moderating role of political affiliation in the relationship between extreme weather experience and climate change perceptions, and critically discuss the implications for efforts to harness personal experiences in promoting climate change engagement. Here, we use the term 'climate change engagement' to describe the gamut of cognitive, affective and behavioural engagement dimensions including awareness, concern and motivation to act (Lorenzoni et al. 2007). The empirical and conceptual considerations that guided our analysis are briefly discussed in the following sections.

1.1. Disentangling 'extreme weather experience' from 'climate change experience' in the context of climate change engagement

The purported association between extreme weather experiences and climate change attitudes appears more consistent when extreme weather experience is operationalised as 'perceived personal experience of climate change or global warming' (e.g., asking survey respondents if they have experienced "any extreme weather conditions that they interpret as caused by long-term, global 
climate change" (Blennow et al. 2012)), compared with unattributed measures of extreme weather experience (e.g. simply asking if respondents have experienced flooding) (Whitmarsh 2011; Bruine de Bruin et al. 2014). Considering the challenges inherent in scientifically attributing any single weather event to global climate change (Hulme 2014), perceptions of a causal relationship between extreme weather and climate change among lay individuals reflects the involvement of subjective appraisal and attribution processes that likely exert unique influences on attitudes, over and above that of mere experience with extreme weather. In other words, 'extreme weather experience' is a step removed from 'perceived personal experience of climate change'. Conflating the links between either of these two constructs and climate change engagement is misleading because it spuriously inflates the inherent value of extreme weather experiences and subsumes the critical intervening roles of other factors that modulate how extreme weather events are interpreted and integrated into individuals' beliefs, feelings and motivations.

1.2. The social construction of extreme weather as indicative of climate change

According to Reser et al. (2014), the interconnection between extreme weather patterns, the intensity and frequency of natural disasters, and the unfolding meteorological and geophysical impacts of climate change have imbued extreme weather events with a powerful 'climate change signal' in the context of human risk perception, experience and understanding. Extreme weather experiences can heighten climate change engagement by confirming pre-existing beliefs, increasing the salience of climate change, and enabling personal realization of the immediacy and reality of the problem among people who perceive this 'signal', (Reser et al. 2012, 2014; Akerlof et al. 2013; Myers et al. 2013). A number of authors have also recommended that extreme weather events can create opportunities to teach people about climate change as individuals may become more attentive and receptive to education efforts following adverse personal experiences with extreme weather (Rudman et al. 2013; Howe et al. 2014; Lang and Ryder 2016). However, extreme weather experiences may fail to produce changes in climate change engagement when the event(s) experienced are not explicitly attributed to climate change; especially when engagement pertains to mitigation actions and policies (e.g., McCright et al. 2014; van der Linden 2014).

Research shows that people situated in the same, or proximate, locations can have remarkably different perceptions of their experiences with the same extreme weather event(s) (Cutler 2015; Shao 2016). As academic debate on the psychological mechanisms that underlie the effects and constitution of extreme weather experiences continues to unfold with new evidence and perspectives, different streams of research have converged on the socially constructed nature of perceived 'extreme weather' with regard to societal interpretation of climatic trends and events (Hulme et al. 2009; Goebbert et al. 2012). There is growing evidence that pre-existing values, beliefs and worldviews have a significant moderating influence on whether or not people perceive salient weather events to be 'extreme' or 
'unusual' (Goebbert et al. 2012; Shao 2016), or perceive their experiences with unusual weather to be consistent with trends expected from climate change (e.g., Stuart Bryce Capstick \& Pidgeon, 2014). Indeed, the influence of political values and identification may eclipse that of objective climate extremes on climate change perceptions in some instances (Marquart-Pyatt et al. 2014). Nonetheless, irrespective of the moderating influence of social and personal psychological attributes, people tend to ascribe undue weight to perceived weather abnormalities; with the result that perceived experiences of abnormal weather, by and large, appear to give rise to greater climate change belief and concern (Zaval et al. 2014).

Objective weather has a weaker influence on climate change engagement than perceived weather (Shao 2016). It seems evident that the impact of extreme weather experiences as triggers of climate change proximization and engagement is inextricably linked to that of the cognitive factors that underlie variability in individuals' predisposition to attribute extreme weather events to climate change. Therefore, it is necessary to identify the attributes that influence the likelihood that individuals will make causal attributions of extreme weather events to climate change, and assess if and how these attributes moderate the relationship between extreme weather experiences and climate change engagement. With these considerations in mind, we revisited previous research by Spence et al. (2011) in which a positive link was found between reported flood experience and preparedness to reduce energy use in a UK national sample.

1.3. Prior research on perceptions of flooding and climate change in the United Kingdom Flooding is expected to be one of the main threats to UK communities resulting from climate change (DoH 2001; Schaller et al. 2016). In a study by Spence et al. (2011), people with experience of local flooding reported greater perceived ability to address climate change (perceived instrumentality), higher levels of climate change concern, less uncertainty that climate change is occurring, and stronger perceptions of local vulnerability to climate change impacts than those without (Figure 1). Additionally, Spence et al. (2011) found that perceived instrumentality, concern and perceived local vulnerability positively mediated a link between flood experience and preparedness to reduce energy use. Based on goal-setting theory (Locke and Latham 2002), they argued that, in addition to increasing perceived vulnerability and concern, experiences of extreme events such as flooding which may be attributed to climate change confer individuals with an increased sense of personal efficacy, which in turn translates into greater preparedness to engage in actions that help tackle the issue. Although Spence et al. (2011) did not directly address the question of attribution, they proffered a statement that: "[the] relationships observed [....] may have developed in people's understandings through the interaction between a series of major flooding events in the UK and the salience accorded to climate change in public life and discourse in recent years" (pg. 48). 
Some of these findings have been replicated in subsequent studies (e.g., Capstick et al., 2015; Demski et al., 2017). Following a run of exceptionally severe storms and flooding across the UK in December 2013 and January 2014, Capstick et al. (2015) conducted a survey of public perceptions of the climate change using a nationally representative sample. Like Spence et al. (2011), they found that people with direct experience of the floods were more likely to see their local area as vulnerable to climate change impacts and were more likely to view climate change as a serious threat to themselves and their family. Most respondents (64\%) in Capstick et al.'s (2015) survey agreed that the floods had been caused in part by climate change, and a greater majority (72\%) agreed that the floods demonstrated what could be expected from climate change in the future. Interestingly, $45 \%$ of respondents in the study agreed with the notion that 'it is impossible to link a single weather event with climate change', compared with 33\% who disagreed. Capstick et al.'s (2015) findings show that a considerable proportion of UK residents are not naïve to the difficulty inherent in scientifically establishing a causal link between extreme weather and climate change, yet many perceive climate change to be implicated in their experience of unusually severe flooding.

Similarly, Demski et al. (2017) found that UK residents with direct experience of flooding as a consequence of the 2013/2014 winter storms reported greater levels of negative emotional responses to flooding, perceived risk from climate change and personal salience of the issue. Interestingly, they also found that some of these changes in perceptions and emotions not only mediated a link between flood experience and behavioural responses to climate change, but also a link between flood experience and adaptation intentions regarding heatwaves - a different weather event potentially linked with climate change. These findings were speculatively interpreted as evidence that flood experiences increase the cognitive availability of climate change (i.e. they make climate change more tangible); and in so doing prompt support for climate change policies and intentions to personally engage in mitigation and adaptation behaviours.

However, other research in the UK (Whitmarsh 2008; Hamilton-Webb et al. 2016) addressing the link between flood experience and climate change engagement has produced some contrasting findings. Prior to Spence et al.'s (2011) study, Whitmarsh (2008) found no significant differences in perceived vulnerability to climate change or actions taken to address the issue between flood and non-flood victims in the south of England. More recently, Hamilton-Webb et al. (2016) found that while flood experience was significantly associated with climate change concern and behavioural responses in a sample of UK farmers, mitigation actions such as reducing energy use and increasing use of minimum tillage were largely being undertaken as part of normal practice rather than with the intention of addressing climate change. In both studies, climate change was the least cited perceived cause of flooding, compared with other locally observable factors such as lack of watercourse maintenance. Though, Hamilton-Webb et al. (2016) observed that farmers who were reducing their energy use were also more likely to believe that climate change is a major cause of flooding in the UK. The authors of 
these two studies concluded that personal values appeared to be more important than experience in determining the way people engage with flooding in the context of climate change.

1.4. The current study: conceptual framework and hypotheses

The notion of climate change is a statistical abstraction. Research suggests that people typically prefer to constitute their attitudes from information gained through experiences of directly observable trends and events than expend the additional amount of cognitive effort required to process abstract climate change information (Weber 2006; Myers et al. 2013). Inferring the evidence of climate change from experience is not only less cognitively demanding than analytical processing of abstract statistical information, it also occurs more rapidly and has a stronger influence on attitudes and perceptions (Myers et al. 2013). However, experiential processing of climate change-related evidence is often guided by values and ideology (Kahan 2013; Hornsey et al. 2016). More specifically, social identity as a function of membership in social groups with shared fundamental values (e.g. political and ideological groups), operates as a filter in climate change information processing and assimilation (Kahan et al. 2011; Fielding and Hornsey 2016).

Political and ideological group membership provides salient beliefs and norms that prescribe and describe prototypical in-group views on key issues (Fielding and Hornsey 2016). When people perceive themselves in terms of membership in such groups, they assimilate to the group prototype i.e., their attitudes and beliefs become regulated by the norms and standards associated with the salient social identity (Rabinovich et al. 2012). According to Hahnel and Brosch (2016), political group identity can be expected to modulate individuals' perception of climate change to the extent that that they influence whether group members perceive relevant events as unnatural or a reason to act. Indeed, research shows that political affiliation and ideological orientation significantly influence the way people perceive flooding and other extreme weather events (Cutler 2015; Hamilton et al. 2016), as well as their climate change beliefs and willingness to act pro-environmentally (McCright and Dunlap 2011; Whitmarsh 2011; Gromet et al. 2013; Hamilton and Stampone 2013; McCright et al. 2016).

On this basis, we hypothesized that political affiliation significantly covaries with the likelihood that UK residents see flooding as linked with climate change (H1), and the way flood experience affects their attitudes toward climate change (H2). We tested these hypotheses by comparing reported flood experience and climate change attitudes among sub-populations of left and right leaning voters in Spence et al.'s (2011) dataset.

\section{Methods}

2.1. Data 
A summary of the sampling, survey instruments development, and data collection procedures is provided in Spence et al.'s (2011) report. The data used in our analysis were supplied by the first author of the report on request.

\subsection{Data analysis}

Using respondents' reported voting intentions, we categorised those who indicated "Labour", "Liberal Democrat" or "Green" as left leaning voters $(N=532)$, and those who indicated "British National Party (BNP)", "Conservative" or "UK Independent Party (UKIP)" as right leaning voters (N $=416$ ). The placement of the parties on the left-right political spectrum was based on data from public polls conducted by YouGov - a major internet-based market research company - in the same year as Spence et al.'s (2011) survey (Dahlgreen 2014). We compared reported flood experience, perceived personal experience with climate change, and climate change attitudes across both groups of voters with chi-square and $t$ tests. We also assessed the equivalence of Spence et al.'s (2011) multiplemediation model (Figure 1) - which links flood experience with preparedness to reduce energy use through perceived instrumentality, concern, uncertainty about climate change and perceived vulnerability - across the two groups with multi-group path analysis.

We specified the multiple-mediation model in AMOS 22 following the description provided by Spence et al. (2011) i.e. all mediator residuals were allowed to co-vary freely and the demographic factors (age, gender and social grade) were included as covariates in the model. We tested the equivalence of the model for right and left-leaning voters by comparing a model in which all structural paths were constrained to be equal for both groups with one in which they were allowed to vary freely using chi-square difference tests. Subsequently, we assessed the equivalence of each path in the model by comparing the fully constrained model with a constrained model in which only one path was allowed to vary freely at a time. The results of the path comparisons are provided in full as supplementary information (Supplementary Figure S1). We estimated the specific indirect effects of flood experience conveyed through the mediators using the PROCESS macro for regression-based tests of mediation, moderation and conditional processes (Hayes 2013) as was done by Spence et al. (2011). Items used in this analysis and descriptive statistics for each group are presented in Table 1.

\subsection{Missing data}

There was a small proportion of missing data $(<5 \%)$ on some of the variables and list-wise deletion was used in the chi-square and $t$-tests. However, we estimated the multiple mediation model in AMOS 22 using two versions of the dataset; one in which list-wise deletion was applied and another in which the missing values were replaced with the regression imputation method (Arbuckle 2013). There were no substantive differences in the results obtained using either dataset. Hence, we report the results obtained using the imputed data below. 


\section{Results}

We found that left-leaning voters were no more likely to report having had a personal experience of local flooding than right-leaning voters $\left(\chi^{2}(1,940)=0.64, p=0.425\right)$. However, the former were more likely to report having noticed signs of climate change in their lifetime $\left(\chi^{2}(2,948)=14.92, p=0.001\right)$, and cite flooding when prompted to state what signs they had witnessed $\left(\chi^{2}(2,948)=11.84, p=0.003\right)$. While this does not directly address the question of whether respondents attributed their recent experience of local flooding to climate change, it provides some support for our hypothesis (H1) that the likelihood of seeing a link between flooding and climate change covaries with political affiliation. There were also significant differences in climate change attitudes between the two categories of voters; with left-leaning voters reporting greater perceived instrumentality, concern, vulnerability to climate change, willingness to reduce energy use and less uncertainty about climate change (Table 1).

Further, in support of our hypothesis (H2), we found that Spence et al.'s (2011) mediation model (Figure 2) of the relationship between flood experience, climate change perceptions and preparedness to reduce energy use was not equivalent for left and right-leaning voters $\left(\Delta \chi^{2}{ }_{(24,934)}=46.05, p=\right.$ 0.004). The total indirect effect of flood experience on preparedness to reduce energy use via climate change perceptions was significant among left-leaning $(B=0.07, \mathrm{SE}=0.03,95 \% \mathrm{CI}(0.02,0.13), N=$ $491)$, but not right-leaning voters $(B=0.07, \mathrm{SE}=0.04,95 \% \mathrm{CI}(-0.01,0.15), N=371)$. Perceived instrumentality $(B=0.04, \mathrm{SE}=0.02,95 \% \mathrm{CI}(0.00,0.08))$ and uncertainty about climate change $(B=$ $0.01, \mathrm{SE}=0.01,95 \% \mathrm{CI}(0.00,0.03))$ significantly mediated the relationship between flood experience and preparedness to reduce energy use only among left-leaning voters. We also found that only the path linking uncertainty about climate change and preparedness to reduce energy use in Spence et al.'s (2011) model differed significantly for left and right-leaning voters $\left(\Delta \chi^{2}{ }_{(1,934)}=6.58, p\right.$ $=0.010)^{2}$. These findings indicate that the likelihood that people see a link between flooding and climate change, and the way flood experience affects their climate change perceptions and action intentions, varies systematically depending on their political affiliation.

\section{Discussion}

The polarization of public views on climate change along political and ideological lines is well documented in the United States (McCright and Dunlap 2011; Bliuc et al. 2015), and to a lesser extent in Europe (McCright et al. 2016). Individuals have a tendency to interpret and assimilate climate change-related information in ways that correspond with their pre-existing values and political loyalties (Kahan 2013; Hornsey et al. 2016). This tendency - broadly termed motivated cognition, is

\footnotetext{
${ }^{2}$ The full path comparison results are presented in Appendix 1 - Supplementary Data
} 
underpinned by the appropriation of normative views and attitudes associated with salient social identities and group memberships as a lens through which information is processed and incorporated into personal beliefs (Fielding and Hornsey 2016; Hahnel and Brosch 2016), and individuals' desire to maintain congruence between their beliefs and fundamental values they share with significant others (Kahan 2013). To an extent, our findings reflect the involvement of motivated cognition in UK residents' interpretation of flooding with regard to climate change.

In line with the cultural cognition thesis (Kahan et al. 2011; Kahan 2013), it appears that people 'learn' from their experiences with flooding in ways that produce climate change attitudes that are consistent with their fundamental values. Where experience of local flooding appeared to contribute indirectly to increasing preparedness to reduce energy use by reducing uncertainty about climate change and increasing perceived instrumentality among left-leaning voters, no such effect was observed among right-leaning voters. It seems plausible that the influence of flood experience on climate change engagement is weaker among right-leaning voters, since this demographic has been shown to have greater levels of climate change scepticism in the UK (Whitmarsh 2011).

Although our analyses showed that left-leaning voters were more likely to report having witnessed signs of climate change and cite flooding as a sign of climate change, it is not clear that the significant indirect relationship between flooding experience and willingness to reduce energy use among this group was simply due to the way they attributed their experience of flooding. In both groups of voters, local flooding experience was positively linked with perceived local vulnerability to climate change and negatively linked with uncertainty that climate change is happening, which suggests that flood experiences have a significant impact on climate change perceptions irrespective of political affiliation (or the underlying values and identities they reflect). However, in contrast to Spence et al.'s (2011) results, flooding experience had no significant link with perceived instrumentality, and the positive link with uncertainty about climate change did not translate to greater willingness to reduce energy use, among right-leaning voters. This may be indicative of biases in respondents' processing of flood experience by their beliefs about the causes of climate change. While left-leaning voters are more likely to believe that climate change is driven by human activities, right-leaning voters tend to see climate change as a natural process (e.g., McCright \& Dunlap, 2011; Weber \& Stern, 2011) Therefore, even though local flood experiences may generally promote perceptions of climate change as a certain and proximate threat, support for mitigation strategies such as reducing energy use may be less likely to result among right-leaning voters with greater levels of pre-existing scepticism about the anthropogenic nature of climate change.

\footnotetext{
${ }^{3}$ Indeed a significantly greater proportion of right-leaning voters (28.61\%) than left-leaning voters (19.73\%) indicated that they believe climate change is not happening/not anthropogenic in the current sample $\left(\chi_{(1)}^{2}=9.92\right.$, $p=0.002)$.
} 
Given an understanding that values and identity function as a filter in information processing (Kahan et al. 2011; Fielding and Hornsey 2016), simply highlighting the links between extreme weather and climate change is unlikely to be a broadly effective strategy for promoting climate change engagement. Information which supports climate change knowledge and understanding is unlikely to be politically neutral (Gavin et al. 2011), and political affiliation can have considerable influence on how individuals interpret their experience with extreme weather in relation to climate change (Givens 2014; Hahnel and Brosch 2016). Identification with a political group makes individuals susceptible to align their judgments and actions to their affiliated political group's standards; to the extent that political affiliation may have a greater influence on climate change-related judgments than the combination of personal experience, values and ideology (Cohen 2003; Hahnel and Brosch 2016).

Therefore, while Spence et al.'s (2011) argument that flood experience confers a sense of personal efficacy and greater preparedness to reduce energy use may hold true for left-leaning voters - whose politics normatively endorse belief in anthropogenic climate change and engagement in mitigation actions, our findings suggest that these outcomes may not be achieved among right-leaning voters whose political identities are more likely to be associated with climate change scepticism.

Nevertheless, drawing on local weather events as a means of proximizing climate change remains a promising strategy. Our analysis showed that flood experience was significantly linked with lower uncertainty about climate change and greater perceived vulnerability to climate change impacts among both left- and right-leaning voters. Educational interventions that link local extreme weather events with global climate change may successfully build on such experiences to help people better understand the causes and consequences of climate change (e.g., Zhao et al. 2013). Additionally, the fluid and context-dependent nature of social identities provides opportunities to circumvent the challenge posed by antagonistic political affiliations by exploiting such resources as in-group messengers, and communication strategies that promote pro-environmental in-group norms and link social identity with pro-environmental outcomes (Fielding and Hornsey 2016). For example, reframing mitigation activities as improving technological and economic advancement, rather than averting climate change risks, has been shown to significantly increase motivation to act proenvironmentally among political groups that typically exhibit high levels of climate change scepticism (e.g., Bain et al. 2012). Similarly, recent research in the UK suggests that appealing to patriotism and the 'conservative' value of reducing waste by framing low-carbon technologies as "Great British Energy" elicits broad support, while social justice framing - a narrative commonly employed in current climate change communication, produced political polarization among audiences (Whitmarsh and Corner 2017).

It should be noted that the current research has some limitations. Firstly, due to the cross-sectional nature of the data, it is impossible to establish causal interrelationships between flood experience, 
climate change perceptions and willingness to reduce energy use among the sample. Although the results are consistent with our proposition that the link between extreme weather experiences and climate change perceptions and action motivations vary systematically depending on political affiliation, longitudinal studies are needed to further substantiate our findings. Secondly, as pointed out by a reviewer, we cannot rule out the possibility that prior experiences with flooding (or other extreme weather events) may have influenced participants' reported voting intentions and climate change attitudes. However, considering that there was no significant difference between left- and right-leaning voters in their reported experiences of local flooding, and left-leaning voters were more likely to cite flooding as a sign of climate change, it seems more likely that political affiliation moderates the interpretation of flood experiences and their consequent effects on attitudes.

The only significant difference (in multigroup path analysis) between left and right-leaning voters in our re-analysis of Spence et al.'s (2011) model was the path linking scepticism with willingness to reduce energy use. Scepticism about the reality and drivers of climate change is plausibly the most politically divisive aspect of climate change perceptions (with consequent implications for individuals' willingness to reduce energy use) in the UK, rather than the attribution of flooding with regard to climate change (e.g., Marquart-Pyatt et al. 2014). Subsequent research exploring whether similar patterns are observed in relation to other mitigation actions could yield some useful insights into determining if reduced uncertainty about climate change as a result of experiences with flooding fails to translate into greater preparedness to reduce energy use specifically, or preparedness to engage in mitigation actions in general, depending on individuals' political affiliation. It would also be informative to determine if experiences with other extreme weather events such, as heatwaves, in the UK affect climate change risk perceptions and uncertainty across different political groupings as was observed with flooding in this study.

\section{Conclusion}

Our results support previous indications that integrating interactions between political affiliation and extreme weather experience into predictive models of mitigation and adaptation intentions can lend valuable nuance and greater accuracy to assessments of the effects of such experiences on climate change engagement in the UK (Capstick et al. 2015b; Demski et al. 2017). Irrespective of the modulating influence of politics, it is unlikely that a strategy of proximizing climate change through experiences with extreme weather alone will be sufficient to build and sustain positive climate change engagement given that a focus on climate change risks can lead to maladaptive responses including desensitization, denial and defensiveness (Brügger et al. 2015). Therefore, more research is needed to determine how extreme weather experiences can be combined with other climate change communication strategies to maximize their positive influence on individuals' attitudes and motivations. 


\section{References}

Akerlof K, Maibach EW, Fitzgerald D, et al (2013) Do people "personally experience" global warming, and if so how, and does it matter? Glob Environ Chang 23:81-91. doi: 10.1016/j.gloenvcha.2012.07.006

Arbuckle JL (2013) IBM SPSS Amos 22 user's guide. IBM Corporation, Armonk

Bain PG, Hornsey MJ, Bongiorno R, Jeffries C (2012) Promoting pro-environmental action in climate change deniers. Nat Clim Chang 2:600-603. doi: 10.1038/nclimate1532

Blennow K, Persson J, Tomé M, Hanewinkel M (2012) Climate change: believing and seeing implies adapting. PLoS One 7:50182. doi: 10.1371/journal.pone.0050182

Bliuc A-M, McGarty C, Thomas EF, et al (2015) Public division about climate change rooted in conflicting socio-political identities. Nat Clim Chang 5:226-229. doi: 10.1038/nclimate2507

Brügger A, Dessai S, Devine-Wright P, et al (2015) Psychological responses to the proximity of climate change. Nat Clim Chang 5:1031-1037. doi: 10.1038/nclimate2760

Bruine de Bruin W, Wong-Parodi G, Morgan MG (2014) Public perceptions of local flood risk and the role of climate change. Environ Syst Decis 34:591-599. doi: 10.1007/s10669-014-9513-6

Capstick SB, Demski C, Sposato RG, et al (2015a) Public perceptions of climate change in Britain following the winter 2013/2014 flooding. Cardiff University, UK.

Capstick SB, Pidgeon NF (2014) Public perception of cold weather events as evidence for and against climate change. Clim Change 122:695-708. doi: 10.1007/s10584-013-1003-1

Capstick SB, Whitmarsh L, Poortinga W, et al (2015b) International trends in public perceptions of climate change over the past quarter century. Wiley Interdiscip Rev Clim Chang 6:35-61. doi: $10.1002 /$ wcc. 321 
Cohen GL (2003) Party Over Policy: The Dominating Impact of Group Influence on Political Beliefs. J Pers Soc Psychol 85:808-822. doi: 10.1037/0022-3514.85.5.808

Cutler MJ (2015) Seeing and believing: the emergent nature of extreme weather perceptions. Environ Sociol 1:293-303. doi: 10.1080/23251042.2015.1085117

Dahlgreen W (2014) Britain's Changing Political Spectrum. In: YouGov. https://yougov.co.uk/news/2014/07/23/britains-changing-political-spectrum/. Accessed $19 \mathrm{Feb}$ 2017

Demski C, Capstick SB, Pidgeon NF, et al (2017) Experience of extreme weather affects climate change mitigation and adaptation responses. Clim Change 140:149-164. doi: 10.1007/s10584016-1837-4

Dessai S, Sims C (2010) Public perception of drought and climate change in southeast England. Environ Hazards 9:340-357. doi: 10.3763/ehaz.2010.0037

DoH (2001) Health effects of climate change in the UK. London: HMSO.

Fielding KS, Hornsey MJ (2016) A social identity analysis of climate change and environmental attitudes and behaviors: Insights and opportunities. Front Psychol 7:121. doi: 10.3389/fpsyg.2016.00121

Gavin NT, Leonard-Milsom L, Montgomery J (2011) Climate change, flooding and the media in Britain. Public Underst Sci 20:422-438. doi: 10.1177/0963662509353377

Givens JE (2014) Sociology: Drivers of climate change beliefs. Nat Clim Chang 4:1051-1052. doi: $10.1038 /$ nclimate 2453

Goebbert K, Jenkins-Smith HC, Klockow K, et al (2012) Weather, climate, and worldviews: The sources and consequences of public perceptions of changes in local weather patterns. Weather Clim Soc 4:132-144. doi: 10.1175/WCAS-D-11-00044.1

Gromet DM, Kunreuther H, Larrick RP (2013) Political ideology affects energy-efficiency attitudes and choices. Proc Natl Acad Sci U S A 110:9314-9. doi: 10.1073/pnas.1218453110

Hahnel UJJ, Brosch T (2016) Seeing Green: A Perceptual Model of Identity-Based Climate Change Judgments. Psychol Inq 27:310-318. doi: 10.1080/1047840X.2016.1215205

Hamilton-Webb A, Manning L, Naylor R, Conway J (2016) The relationship between risk experience and risk response: a study of farmers and climate change. J Risk Res 1-15. doi: 10.1080/13669877.2016.1153506

Hamilton LC, Stampone MD (2013) Blowin' in the wind: Short-term weather and belief in 
anthropogenic climate change. Weather Clim Soc 5:112-119. doi: 10.1175/WCAS-D-12$\underline{00048.1}$

Hamilton LC, Wake CP, Hartter J, et al (2016) Flood realities, perceptions and the depth of divisions on climate. Sociology 50:913-933. doi: 10.1177/0038038516648547

Hayes AF (2013) Introduction to mediation, moderation, and conditional process analysis. Guildford Press, New York

Hornsey MJ, Harris EA, Bain PG, Fielding KS (2016) Meta-analyses of the determinants and outcomes of belief in climate change. Nat Clim Chang 6:622-626. doi: 10.1038/nclimate2943

Howe PD, Boudet H, Leiserowitz A, Maibach EW (2014) Mapping the shadow of experience of extreme weather events. Clim Change 127:381-389. doi: 10.1007/s10584-014-1253-6

Hulme M (2014) Attributing weather extremes to "climate change": A review. Prog Phys Geogr 38:499-510. doi: 10.1177/0309133314538644

Hulme M, Dessai S, Lorenzoni I, Nelson DR (2009) Unstable climates: Exploring the statistical and social constructions of "normal" climate. Geoforum 40:197-206. doi:

10.1016/j.geoforum.2008.09.010

Jones C, Hine DW, Marks ADG (2017) The future is now: Reducing psychological distance to increase public engagement with climate change. Risk Anal 37:331-341. doi:

10.1111/risa. 12601

Kahan DM (2013) Ideology, motivated reasoning, and cognitive reflection. Judgm Decis Mak 8:407424. doi: $10.2139 / \mathrm{ssrn} .2182588$

Kahan DM, Jenkins-Smith HC, Braman D (2011) Cultural cognition of scientific consensus. J Risk Res 14:147-174. doi: 10.1080/13669877.2010.511246

Konisky DM, Hughes L, Kaylor CH (2015) Extreme weather events and climate change concern. Clim Change 134:533-547. doi: 10.1007/s10584-015-1555-3

Lang C, Ryder JD (2016) The effect of tropical cyclones on climate change engagement. Clim Change 135:625-638. doi: 10.1007/s10584-015-1590-0

Locke EA, Latham GP (2002) Building a practically useful theory of goal setting and task motivation: A 35-year odyssey. Am Psychol 57:705-717. doi: 10.1037/0003-066X.57.9.705

Lorenzoni I, Nicholson-Cole S, Whitmarsh L (2007) Barriers perceived to engaging with climate change among the UK public and their policy implications. Glob Environ Chang 17:445-459. doi: 10.1016/j.gloenvcha.2007.01.004 
Marquart-Pyatt ST, McCright AM, Dietz T, Dunlap RE (2014) Politics eclipses climate extremes for climate change perceptions. Glob Environ Chang 29:246-257. doi:

10.1016/j.gloenvcha.2014.10.004

McCright AM, Dunlap RE (2011) The politicization of climate change and polarization in the American public's views of global warming, 2001-2010. Sociol Q 52:155-194. doi: 10.1111/j.1533-8525.2011.01198.x

McCright AM, Dunlap RE, Marquart-Pyatt ST (2016) Political ideology and views about climate change in the European Union. Env Polit 25:338-358. doi: 10.1080/09644016.2015.1090371

McCright AM, Dunlap RE, Xiao C (2014) The impacts of temperature anomalies and political orientation on perceived winter warming. Nat Clim Chang 4:1077-1081. doi: $10.1038 /$ nclimate 2443

McDonald R, Chai HY, Newell B (2015) Personal experience and the "psychological distance" of climate change: An integrative review. J. Environ. Psychol. 44:109-118.

Myers TA, Maibach EW, Roser-Renouf C, et al (2013) The relationship between personal experience and belief in the reality of global warming. Nat Clim Chang 3:343-347. doi: 10.1038/nclimate1754

Rabinovich A, Morton TA, Postmes T, Verplanken B (2012) Collective self and individual choice: the effects of inter-group comparative context on environmental values and behaviour. Br J Soc Psychol 51:551-69. doi: 10.1111/j.2044-8309.2011.02022.x

Reser JP, Bradley GL, Ellul MC (2014) Encountering climate change: "Seeing" is more than "believing.” Wiley Interdiscip Rev Clim Chang 5:521-537. doi: 10.1002/wcc.286

Reser JP, Bradley GL, Glendon AI, et al (2012) Public risk perceptions, understandings, and responses to climate change and natural disasters in Australia and Great Britain. Gold Coast, Queensland: Griffith University, National Climate Change Adaptation Research Facility. www.nccarf.edu.au/publications/public-risk-perceptions-final

Rudman LA, McLean MC, Bunzl M (2013) When Truth Is Personally Inconvenient, Attitudes Change: The Impact of Extreme Weather on Implicit Support for Green Politicians and Explicit Climate-Change Beliefs. Psychol Sci. doi: 10.1177/0956797613492775

Schaller N, Kay AL, Lamb R, et al (2016) Human influence on climate in the 2014 southern England winter floods and their impacts. Nat Clim Chang 6:627-634. doi: 10.1038/nclimate2927

Shao W (2016) Are actual weather and perceived weather the same? Understanding perceptions of local weather and their effects on risk perceptions of global warming. J Risk Res 19:722-742. 
doi: 10.1080/13669877.2014.1003956

Spence A, Poortinga W, Butler C, Pidgeon NF (2011) Perceptions of climate change and willingness to save energy related to flood experience. Nat Clim Chang 1:46-49. doi: 10.1038/nclimate1059

Spence A, Poortinga W, Pidgeon NF (2012) The psychological distance of climate change. Risk Anal 32:957-972. doi: 10.1111/j.1539-6924.2011.01695.x

Taylor A, de Bruin WB, Dessai S (2014) Climate Change Beliefs and Perceptions of Weather-Related Changes in the United Kingdom. Risk Anal 34:1995-2004. doi: 10.1111/risa.12234

van der Linden S (2014) The social-psychological determinants of climate change risk perceptions, intentions and behaviours: A national study. London School of Economics and Political Science

Weber EU (2006) Experience-based and description-based perceptions of long-term risk: why global warming does not scare us (yet). Clim Change 77:103-120. doi: 10.1007/s10584-006-9060-3

Weber EU, Stern PC (2011) Weber Public understanding of climate change in the United States. Am Psychol 66:315-328. doi: 10.1037/a0023253

Whitmarsh L (2008) Are flood victims more concerned about climate change than other people? The role of direct experience in risk perception and behavioural response. J Risk Res 11:351-374. doi: 10.1080/13669870701552235

Whitmarsh L (2011) Scepticism and uncertainty about climate change: dimensions, determinants and change over time. Glob Environ Chang 21:690-700. doi: 10.1016/j.gloenvcha.2011.01.016

Whitmarsh L, Corner A (2017) Tools for a new climate conversation: A mixed-methods study of language for public engagement across the political spectrum. Glob Environ Chang 42:122-135. doi: 10.1016/j.gloenvcha.2016.12.008

Zaval L, Keenan EA, Johnson EJ, Weber EU (2014) How warm days increase belief in global warming. Nat Clim Chang 4:143-147. doi: 10.1038/nclimate2093

Zhao X, Maibach EW, Gandy J, et al (2013) Climate Change Education Through TV Weathercasts: Results of a Field Experiment. Bull Am Meteorol Soc 95:117-130. doi: 10.1175/BAMS-D-1200144.1 


\section{Tables}

Table 1. Experience and climate change measures with descriptive statistics for left and right-leaning voters

\begin{tabular}{|c|c|c|c|c|}
\hline \multirow{5}{*}{$\begin{array}{l}\text { Have you personally } \\
\text { experienced flooding } \\
\text { in your local area } \\
\text { recently or not? } \\
\text { Total }(N)\end{array}$} & & \multicolumn{2}{|c|}{ Political Affiliation } & \multirow{2}{*}{ Total $(N)$} \\
\hline & & Left-Leaning & Right-Leaning & \\
\hline & Yes & 113 & 98 & 211 \\
\hline & No & 413 & 316 & 729 \\
\hline & Pearson $X_{(1)}^{2}=0.64, p=0.425$ & 526 & 414 & 940 \\
\hline \multirow{3}{*}{$\begin{array}{l}\text { Have you personally } \\
\text { noticed any signs of } \\
\text { climate change during } \\
\text { your lifetime? }\end{array}$} & Yes & 339 & 219 & 558 \\
\hline & No & 173 & 186 & 359 \\
\hline & Don't Know & 20 & 11 & 31 \\
\hline Total $(N)$ & Pearson $X_{(2)}^{2}=14.92, p=0.001$ & 532 & 416 & 948 \\
\hline Cited sign of climate & No sign witnessed & 193 & 197 & 390 \\
\hline change & Other event cited & 284 & 183 & 467 \\
\hline & Flooding cited & 55 & 36 & 91 \\
\hline Total $(N)$ & Pearson $X_{(2)}^{2}=11.84, p=0.003$ & 532 & 416 & 948 \\
\hline Construct & Items $^{\dagger}$ & \multicolumn{2}{|c|}{$M(S D)^{\beta}$} & $t(d f)$ \\
\hline $\begin{array}{l}\text { Perceived } \\
\text { instrumentality } \\
(\alpha=0.76)\end{array}$ & $\begin{array}{l}\text { 'I can personally help to reduce } \\
\text { climate change by changing my } \\
\text { behaviour, } \\
\text { 'I personally feel that I can make } \\
\text { a difference with regard to } \\
\text { climate change' }\end{array}$ & $3.58(1.04)$ & $3.17(1.07)$ & $5.70_{(828.21)} * * *$ \\
\hline $\begin{array}{l}\text { Concern about climate } \\
\text { change }\end{array}$ & $\begin{array}{l}\text { 'How concerned if at all are you } \\
\text { about climate change, sometimes } \\
\text { referred to as global warming?' }\end{array}$ & $3.07(0.86)$ & $2.77(0.96)$ & $4.88(791.73)^{* * *}$ \\
\hline $\begin{array}{l}\text { Uncertainty over } \\
\text { climate change }\end{array}$ & $\begin{array}{l}\text { 'I am uncertain that climate } \\
\text { change is really happening' }\end{array}$ & $2.30(1.21)$ & $2.62(1.23)$ & $-3.91_{(833.50)} * * *$ \\
\hline Perceived local & & $3.34(1.15)$ & $3.12(1.22)$ & $2.04(884)^{*}$ \\
\hline
\end{tabular}


vulnerability

Preparedness to reduce energy use
'My local area is likely to be affected by climate change'

I am prepared to greatly reduce my energy use to help tackle climate change'
$3.72(1.03)$

$3.43(1.10)$

$4.07_{(813.81)}{ }^{* * *}$

${ }^{\dagger}$ Responses to perceived instrumentality, uncertainty, perceived local vulnerability and preparedness to reduce energy use items were recorded using a 5 -point scale $(1=$ strongly disagree, $5=$ strongly agree $)$; concern about climate change was recorded with a 4-point scale $(1=$ not at all concerned, $4=$ very concerned), ${ }^{\beta}$ For all t-tests Left-leaning $N=494$; Right-leaning $N=391,{ }^{*} p<0.05,{ }^{* * *} p<0.001$.

\section{Figures}

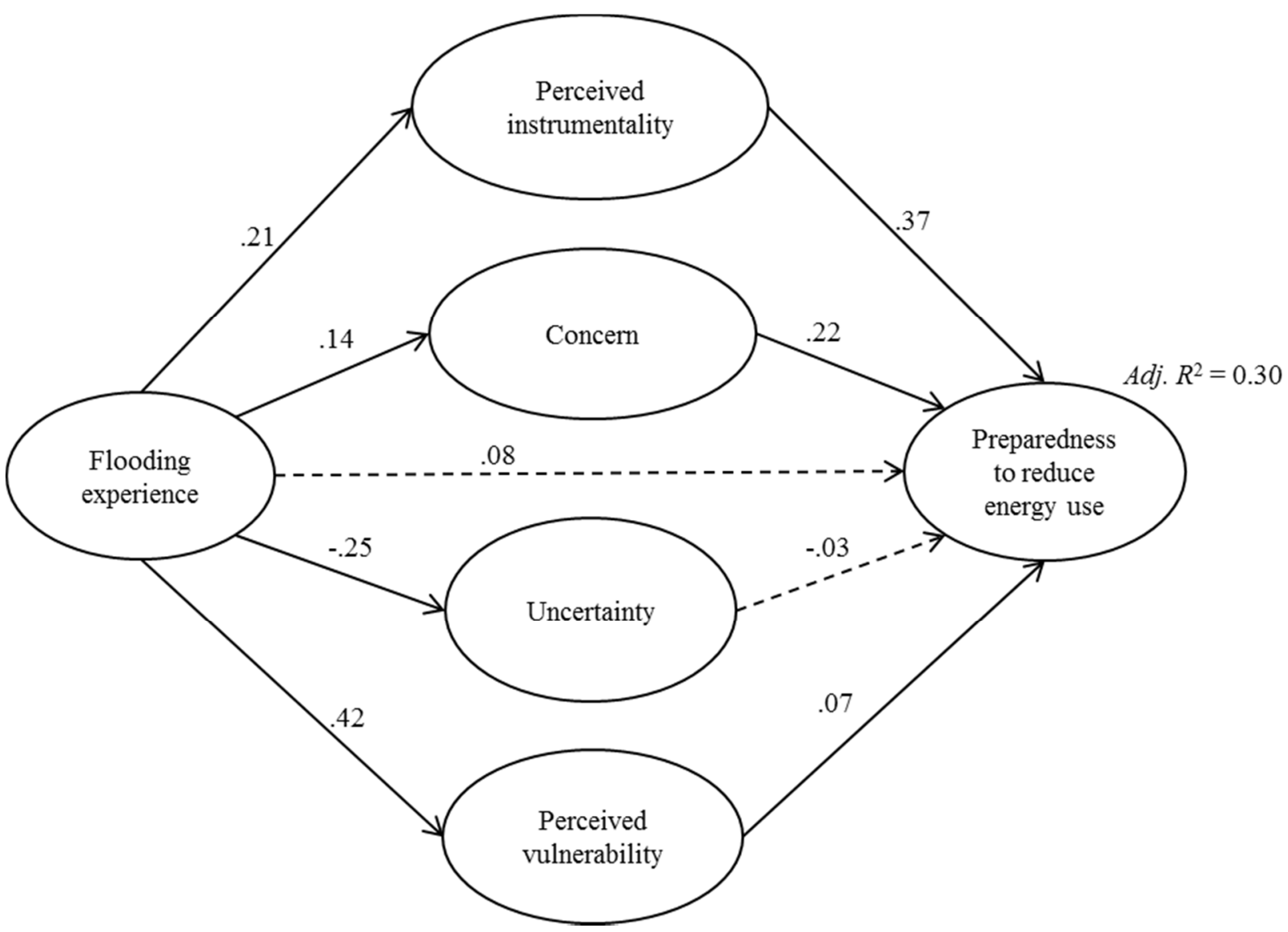

Figure 1. Effect of flood experience on preparedness to reduce energy use mediated by perceived instrumentality, concern, uncertainty and perceived vulnerability. Age, gender and socio-economic grade were included as covariates in the analysis and observed effects are net of their impact. Values are unstandardized regression estimates with solid lines indicating paths significant at $p<0.05$ (Adapted from Spence et al. 2011). 


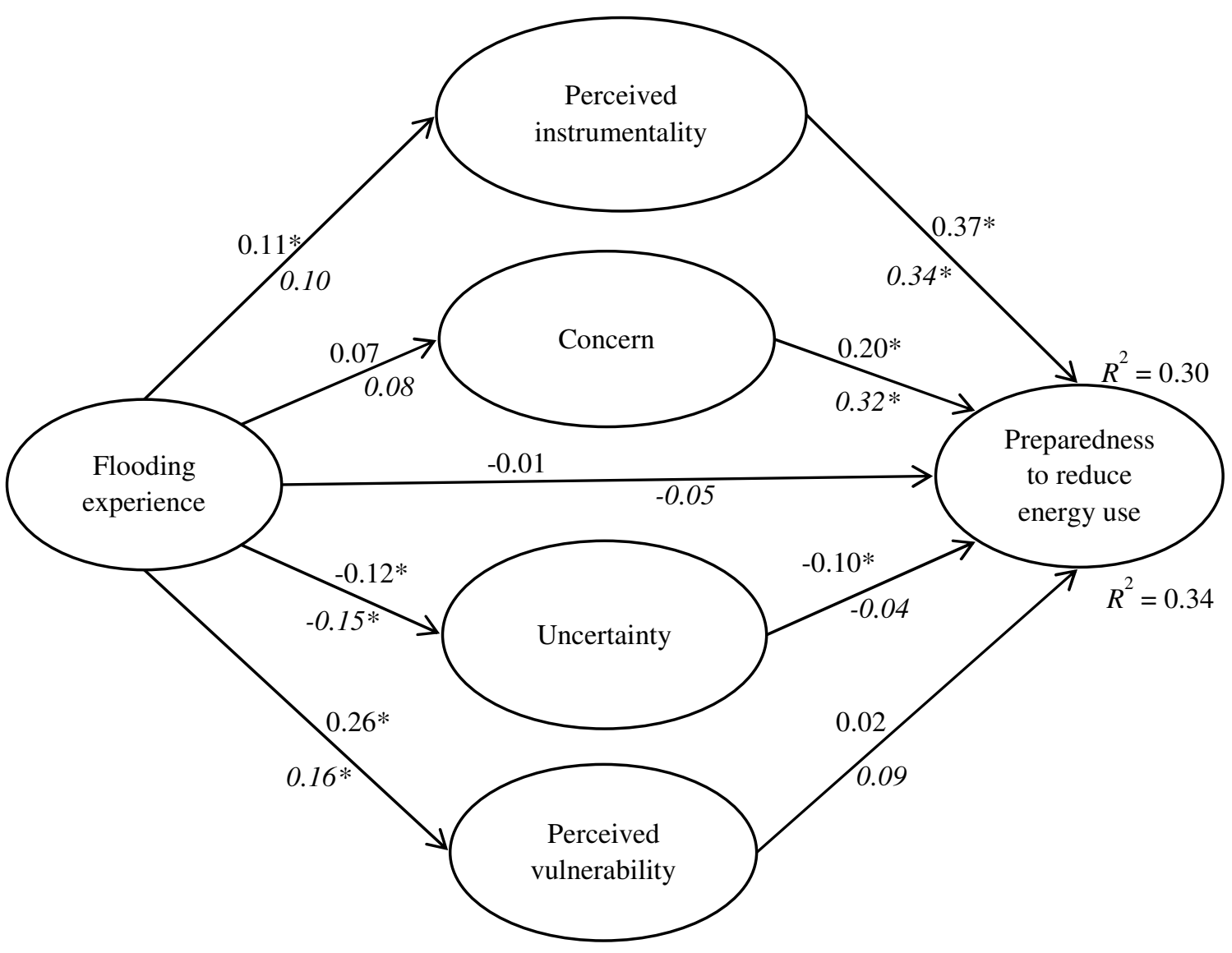

Figure 2. Effect of flooding experience on preparedness to reduce energy mediated by perceived instrumentality, concern, uncertainty and perceived vulnerability. Italicized values below the paths are unstandardized regression estimates for right-leaning voters (Conservative, BNP, UKIP; N = 400), and values above paths are unstandardized regression estimates for left-leaning voters (Labour, Liberal Democrat, Green; $\mathrm{N}=532$ ). Estimates are based on bias-corrected 95\% confidence intervals using 1,000 bootstrap resamples. “*” denotes paths significant at $p<0.05$. 